\title{
Design and Realization of a Discretized Photovoltaic System
}

\author{
E. Baghaz, M. Melhaoui, K. Kassmi" \\ LETAS, Department of Physics, Faculty of Science, University Mohamed the First, Oujda 60000, Morocco \\ *Corresponding Author: khkassmi@yahoo.fr
}

Copyright $@ 2014$ Horizon Research Publishing All rights reserved.

\begin{abstract}
In this paper, we propose an analysis of the structure and functioning in the Pspice simulation and experiment of a discretized photovoltaic (PV) system. This system is formed by two DC/DC Boost converter connected in series. Its role is to transfer electrical energy from two PV generators through two adaptation stages (upper and lower stages). We proposed a circuit control of the power switch of the DC/DC converter, specifically, the upper stage. The results show a good agreement between simulation and experience of electrical values (voltage, current, power) of each block of the PV system. The good performance of each stage $(>90 \%)$ and the complete PV system show that this architecture can provide an innovative solution in terms of reliability and performance improvement chain PV conversion.
\end{abstract}

Keywords Discretzed Photovoltaic System; DC/DC converter in series; Commands of the DC/DC Converter, Circuit of Shaping of the PWM signal; Pspice Simulator; Adaptation; Efficiency

\section{Introduction}

The future of the photovoltaic (PV) industry through lower costs of electricity generation and optimization of production is needed. These two issues require high performance PV systems with a very high efficiency. The classic PV systems (one or more PV panels with a single stage of adaptation provided with the MPPT command [1-4]) have a satisfactory efficiency; however, searching the maximum power point is more complex and requires a broader search to avoid operation around a false maximum power point (MPP). This could occur when there is an inhomogeneous sunlight or a dysfunction of the panels [5]. In addition, if one of the adaptation stages fails all the energy produced will be lost. To overcome this problem, the discretization of the PV panels, where each panel has its own adaptation stage seems an advantageous solution in order to increase reliability and the electrical production PV [1-11].
The works made in the literature show well the interest of the discretized systems realization for the autonomous installations [6-11] as well as for the injection on the distribution network [5]. Every PV panel (or field of PV panel) possesses its own adaptation system (Converter DC/DC, MPPT commands). However, we find few or no extensive studies on the realization and the functioning of a complete PV system formed by $\mathrm{PV}$ panels, DC/DC converters and commands of maximization of the powers supplied by panels (MPPT commands) [1-4]. This is due to a mutual dependence of the functioning of adaptation stages, in relation to each other, and particularly to control the power switch of each DC/DC converter of each stage [5-11]. In this context, in order to clarify and better understand the discretized systems functioning, we propose the study, in depth; the distributed architecture consists of two PV panels, where each panel has its own stage adaptation. Each stage consists of a DC-DC Boost (or buck) converter controlled by an MPPT command.

In this paper, we study the feasibility of such a discretized PV system in Pspice simulator and experiment. We present the results of the functioning of the complete PV system with two adaptation stages. Particular attention will be attached to the design of a power switch command circuit of Boost's DC/DC converters of every stage. The feasibility of the PV system will be deduced by analysing the efficiency of each stage and the complete discretized PV system.

\section{Structure and Functioning of the Discretized PV System in Two Stages}

Figure 1 represents the synoptic diagram of the discretized photovoltaic system (PV), constituted by two adaptation stages. Every stage is constituted by:

- PV panels, in monocrystalline silicon, formed by 36 cells in series (Fig.2) [1-4,12-13]. As shown in the Figure 2, a PV cell is formed by the current generator $\mathrm{I}_{\mathrm{CC}}$ (short-circuit current), the diode (D), the shunt resistance $\left(R_{S h}\right)$, and series resistance $\left(R_{S}\right)$. The current of the diode depends on the technological 
parameters and of the temperature $(\mathrm{T})$ according to the expression:

$$
\mathrm{I}_{\mathrm{D}}=\mathrm{I}_{\mathrm{S}}(\mathrm{T}) \bullet \exp \left(-\frac{\mathrm{q} \bullet \mathrm{V}_{\mathrm{D}}}{\mathrm{K}_{\mathrm{B}} \bullet \mathrm{T}}\right.
$$

Where:

VD: voltage at diode terminals,

IS (T): saturation current,

$\mathrm{q}$ : charge of the free electron,

KB: Boltzmann constant.

From the comparison of the results of simulations to those provided by the manufacturer, we have deduced various parameters from the diode and $\mathrm{PV}$ cell $\left(\mathrm{R}_{\mathrm{S}}\right.$ and $R_{S h}$ ), and dependence of the short-circuit current $\left(\mathrm{I}_{\mathrm{CC}}\right)$ with solar radiation $\left(\mathrm{Le}\left(\mathrm{W} / \mathrm{m}^{2}\right)\right)$ [12-13]. In Figure 3, we have represented the typical experimental and simulated power-voltage characteristics according to the illumination. These results show that the PV panel can provide in standard test conditions (STC) a power of $55 \mathrm{~W}$, a current of $4.2 \mathrm{~A}$ and a voltage of $13 \mathrm{~V}$.

- A load which can be batteries or variable resistance. In this last case, we fixed the values of the resistance superior to the optimal resistance of the PV panel for a given illumination and temperature [1-4].

- The two power stages (upper and lower stage). Each stage is formed by a BOOST DC-DC converter (Figure 4) for applications requiring output voltages higher than optimal PV panels [1-4]. It is dimensioned in continuous mode at a frequency $\mathrm{f}=1$ / $\mathrm{T}=10 \mathrm{kHz}$ ( $\mathrm{T}$ : period), the input currents of $5 \mathrm{~A}$, a power of $100 \mathrm{~W}$ and undulations of the input voltages (output) of the order of $100 \mathrm{mV}(20 \mathrm{mV})$. This application requires the use of power switch of the MOSFET type that has interesting performance (low voltage drop and resistor in the ON state...). During the functioning of the converter:

$\checkmark$ The variation of the inductor current obeys the equations:

- - During the closure of switches,

$$
\frac{\mathrm{di}_{\mathrm{L}}}{\mathrm{dt}}=\frac{\mathrm{Vpv} 1}{\mathrm{~L}}=\frac{\mathrm{Vpv} 2}{\mathrm{~L}}
$$

- - During the opening of switches,

$$
\frac{\mathrm{di}_{\mathrm{L}}}{\mathrm{dt}}=\frac{\mathrm{Vpv1}-\mathrm{Vs} 1}{\mathrm{~L}}=\frac{\mathrm{Vpv} 2-\mathrm{vs} 2}{\mathrm{~L}}
$$

The undulation of the inductor current is a function of the duty cycles $\alpha 1$ and $\alpha 2$ :

$$
\Delta \mathrm{iL}=\frac{\mathrm{Vpv} 1 \cdot \alpha 1}{\mathrm{~L} \cdot \mathrm{f}}=\frac{\mathrm{Vpv} 2 \cdot \alpha 2}{\mathrm{~L} \cdot \mathrm{f}}
$$

In our study, we followed the operation of each DC/DC converter based on the relations bind the electrical quantities of inputs (Vpv1, Vpv2, Ipv1, Ipv2) and those of the output (Vs1, Vs2, Is1, Is2) in function of the duty cycles $\alpha 1$ and $\alpha 2$ [1-4]:

$$
\begin{aligned}
& \text { Vs1 }=\frac{\text { Vpv1 }}{(1-\alpha 1)}, \text { Vs2 }=\frac{\text { Vpv2 }}{(1-\alpha 2)} \\
& \text { Is1 }=(1-\alpha 1) \bullet I p v 1, \quad \text { Is2 }=(1-\alpha 2) \bullet \text { Ipv2 }
\end{aligned}
$$

From these equations, we can deduce the overall functioning of the PV system by the relations:

$$
\begin{aligned}
\mathbf{V s} & =\frac{\mathrm{Vpv} 1}{(1-\alpha 1)}+\frac{\mathrm{Vpv} 2}{(1-\alpha 2)}, \\
& \text { Is }=\mathbf{I s 1}=\mathbf{I s 2} \\
& =(1-\alpha 1) \cdot \mathrm{Ipv1} \\
& =(1-\alpha 2) \cdot \mathrm{Ipv2}
\end{aligned}
$$

In the discretized systems, the problem posed is the control of the upper stage switch since it has a reference voltage (Vref $=$ Vs1) floating and dependent on the lower stage. To do this, we have developed a circuit coupled with the classic Driver to control the opening and the closure of the switch on the upper stage as a function of illumination and throughout the day of the functioning of the PV system. It should be noted that all components of control circuits and control are biased by the $12 \mathrm{~V}$ battery of the PV system.

- A manual MPPT command (Figure 5) formed by an oscillator which generates a saw tooth signal frequency of $10 \mathrm{kHz}$ [2], a variable DC voltage generator and a comparator which generates a PWM signal of variable duty cycle $(\alpha)$ by comparing the saw tooth signal and the DC voltage [2]. In this work, we have adopted this type of control to analyze in depth the operation of two DC/DC converters in continuous operation and ensure proper functioning of the overall discretized PV system.

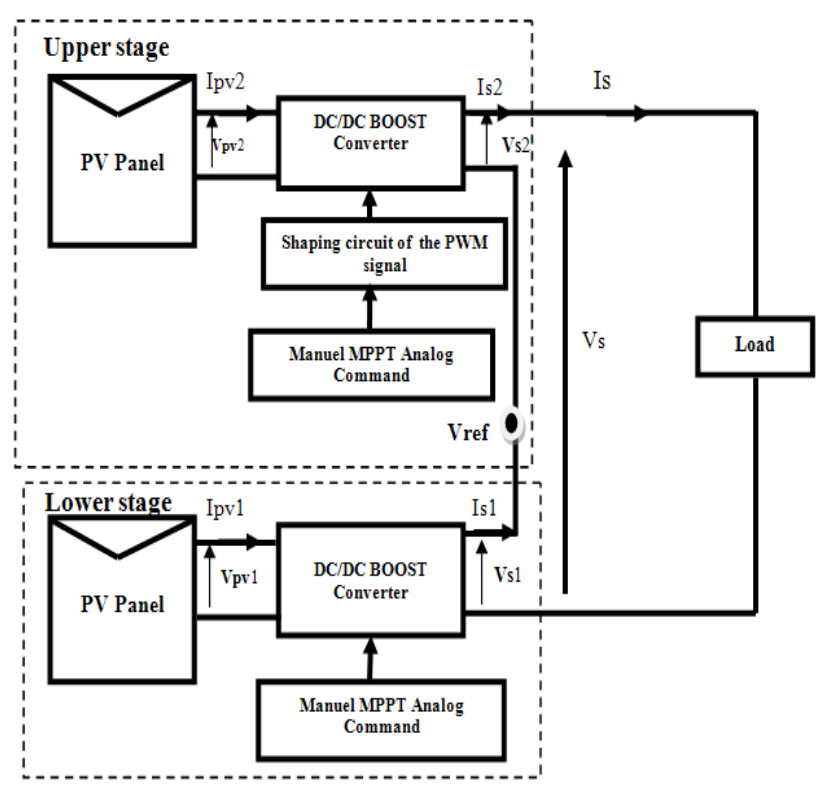

Figure 1. Block diagram of a discretized PV system with two stages (low and high) 


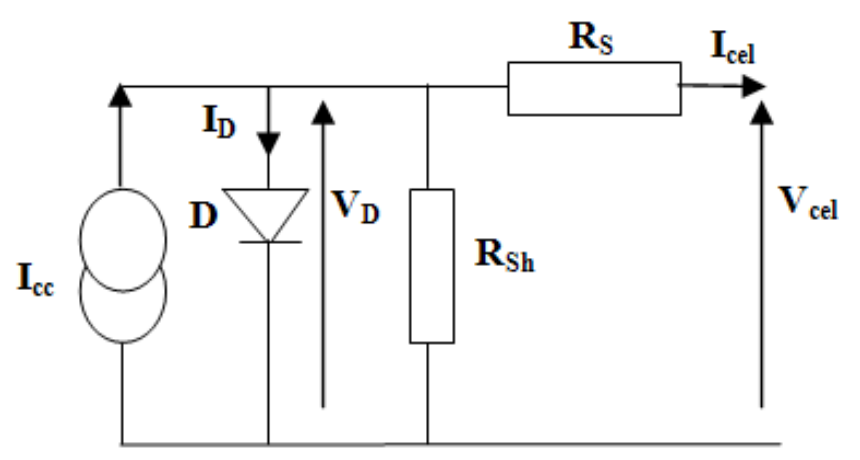

Figure 2. Electric diagram of a Photovoltaic cell

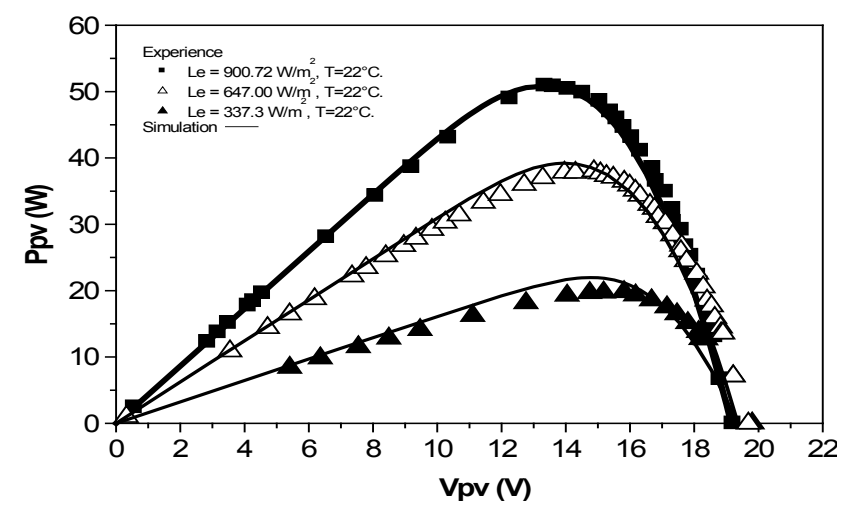

Figure 3. Electric Characteristics powers-voltages experimental and simulated output voltage of the PV panel a function of illumination for a temperature of $22^{\circ} \mathrm{C}$

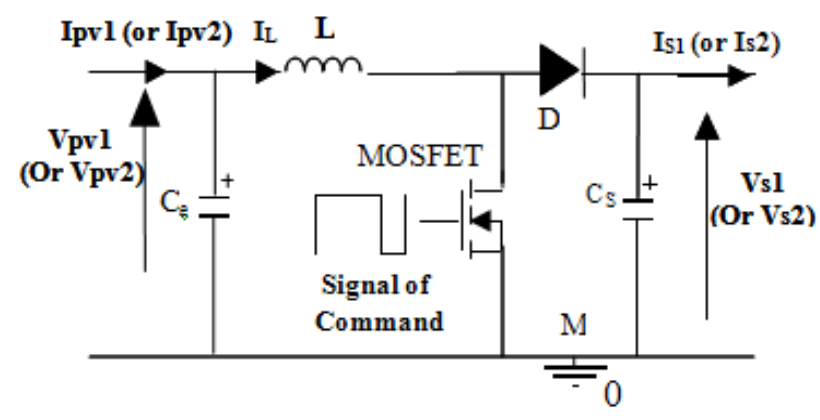

Figure 4. Structure of the DC / DC Boost Converter

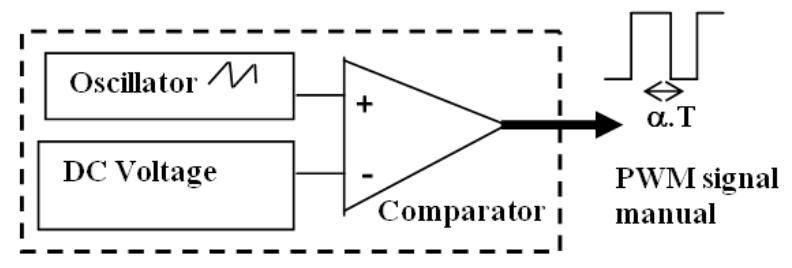

Figure 5. Manual MPPT command

\section{Analysis of Discretized PV System in the Pspice Simulator}

\subsection{Functioning of DC / DC converters}

We implemented the PV system of Figure 1 in the Pspice simulator for an illumination of $700 \mathrm{~W} / \mathrm{m}^{2}$, temperature of $30^{\circ} \mathrm{C}$, a load of $50 \Omega$ and duty cycle $\alpha 1=\alpha 2=\alpha=0.5$. Then, we plotted in Figure 6 the different signals of each DC/DC converter of the PV system. These results show that the functioning depends on the command of the switches of every DC/DC converter:

- $\quad$ switch (MOSFET) of the lower stage has a source connected to ground. It is controlled by the manual MPPT command which generates a signal of frequency of $10 \mathrm{kHz}$, amplitude of $10 \mathrm{~V}$ and duty cycle of 0.5 (Figure 6. A1). However, the source of the switch of the upper stage is floating. The output of the MPPT command is not enough to control the switch. To take account of this floating source, we inserted between the switch and the manual MPPT command a circuit that takes into account the floating source and improves the shape and the amplitude of the PWM signal controlling the switch. Under the conditions of our simulations, the shape of the PWM signal generated by this circuit is shown in Figure 6. A21 (it varies from $0 \mathrm{~V}$ to $35 \mathrm{~V}$ ). This is more than enough to control the opening and closing switch the top stage (Vgs varies from $-30 \mathrm{~V}$ and $5 \mathrm{~V}$ ) (Figure 6. A22).

- After a transient of $50 \mathrm{~ms}$, all the electrical quantities in the input (Vpv1, Ipv1, Vpv2, Ipv2) and in the output (Vs1, Is1, Vs2, Is2) converters are saturated around their corresponding duty cycle values of 0.5 (Figures 6. B1, B2, C1 and C2). The total voltage across the load $(\mathrm{Vs}=60 \mathrm{~V})$ is the sum of the voltages at the output of each converter $(\mathrm{Vs} 1=$ $30.09 \mathrm{~V}, \mathrm{Vs} 2=30.09 \mathrm{~V})$. The current flowing in the load (Is $=1.18 \mathrm{~A})$ is the one that flows at the output of each converter $(\mathrm{Is} 1=\mathrm{Is} 2=1.18 \mathrm{~A})$. These are in good agreement with the relations that govern the functioning of converters (relations 2-5).

- When the two switches are closed (during $\alpha \mathrm{T}$ ):

$\checkmark$ The output voltage of each switch is zero (Figure 6. D1 and D2): $\quad \mathrm{Vds}=0 \mathrm{~V}$,

$\checkmark \quad$ The potential difference across each inductor is (Figure 6. E1 and E2): $\mathrm{VL} 1=\mathrm{Vpv} 1=15.1 \mathrm{~V}, \mathrm{VL} 2=\mathrm{Vpv} 2=15.1 \mathrm{~V}$

$\checkmark$ The charging current of the inductors is one that crosses the switches (Figures 6. F1, F2, G1 and G2).

- When the two switches are open (during T- $\alpha \mathrm{T}$ ):

$\checkmark$ The voltage of output of every switch is equal to that of the output as the diodes lead (Figures 6. D1 and D2):

$\mathrm{Vds} 1=\mathrm{Vs} 1=30.09 \mathrm{~V}, \mathrm{Vds} 2=\mathrm{Vs} 2=30.09 \mathrm{~V}$,

$\checkmark$ The potential difference across each inductor is (Figures 6. E1 and E2):

$\mathrm{VL} 1=\mathrm{Vpv} 1-\mathrm{Vs} 1=-15 \mathrm{~V}, \mathrm{VL} 2=\mathrm{Vpv} 2-\mathrm{Vs} 2=$ $-15 \mathrm{~V}$

$\checkmark$ The discharge current of the inductor is that flowing through each switch (Figures 6. F1, 
F2, G1 and G2)

From plots of the currents (Figures 6. G1 and G2), we can deduce that each converter operates in continuous mode and the value of the current variation $\mathrm{I}_{\mathrm{L}}$ with time $\left(\left|\frac{\mathrm{di}_{\mathrm{L}}}{\mathrm{dt}}\right| \approx 3.7510^{4} \mathrm{~A} / \mathrm{S}\right)$ and the current undulation $(1.88 \mathrm{~A})$ is in good agreement with those deduced by the relations 2 , 3 and $4: 3.7710^{4} \mathrm{~A} / \mathrm{S}$ and $1.88 \mathrm{~A}$.

A1 : PWM1 orVgs1.

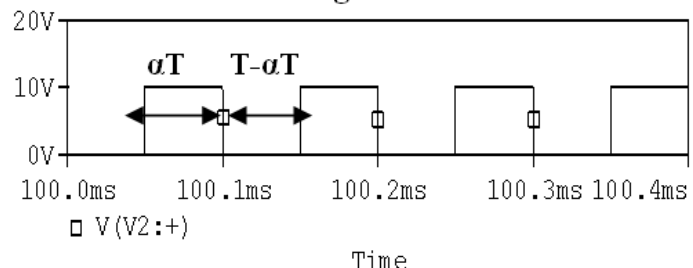

Time
The overall results in the PSpice simulator shows both the validation of relations 2-5 and the good functioning of each component of the two converters in series when their switches are controlled by manual MPPT command and the circuit of shaping. Thus, we propose that this circuit is essential for discretized PV systems of several stages.

A22 : Vgs2.

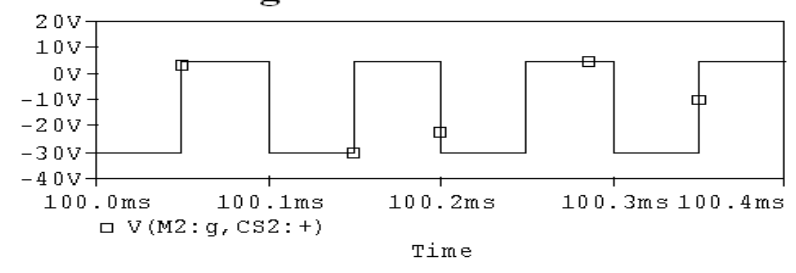

B1
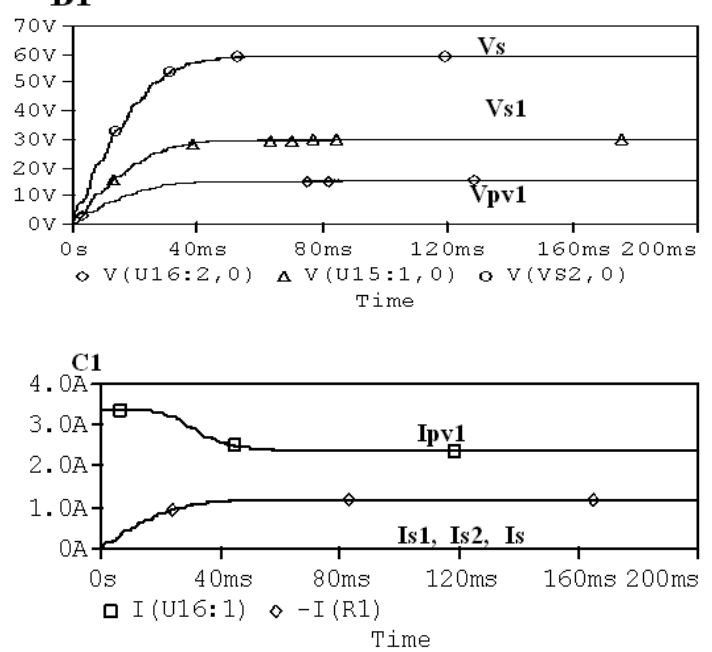

D1

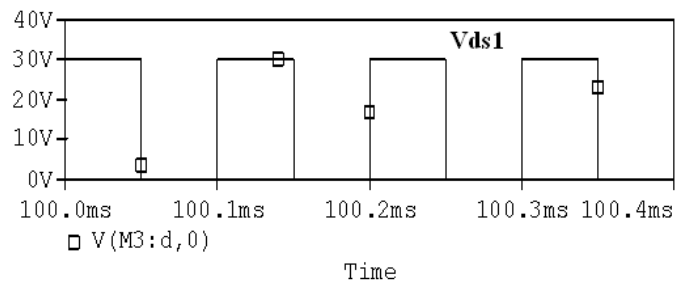

B2
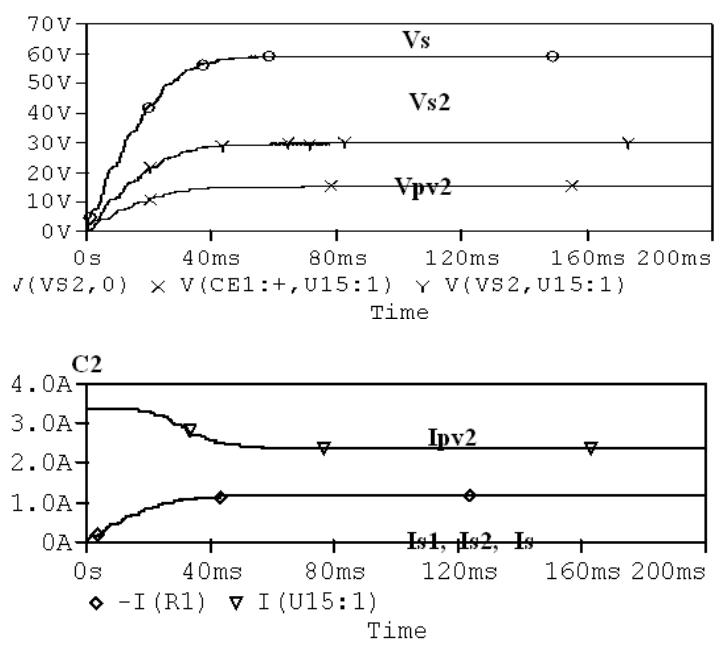

D2

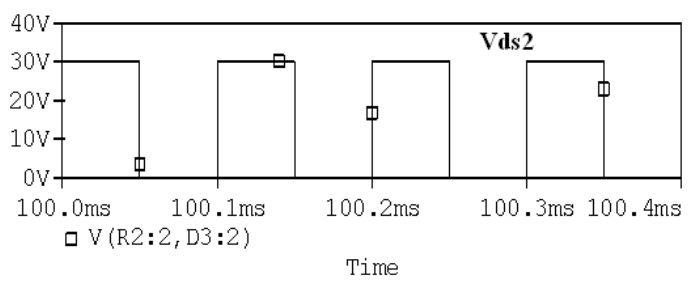


E1

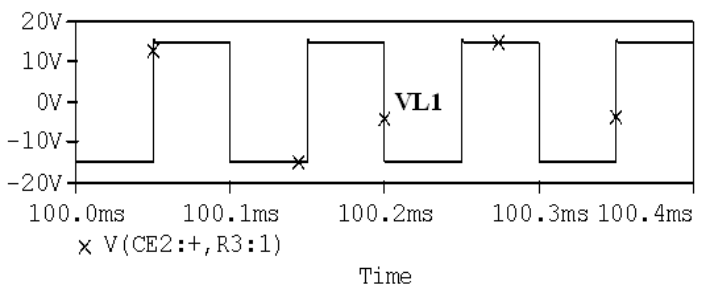

F1
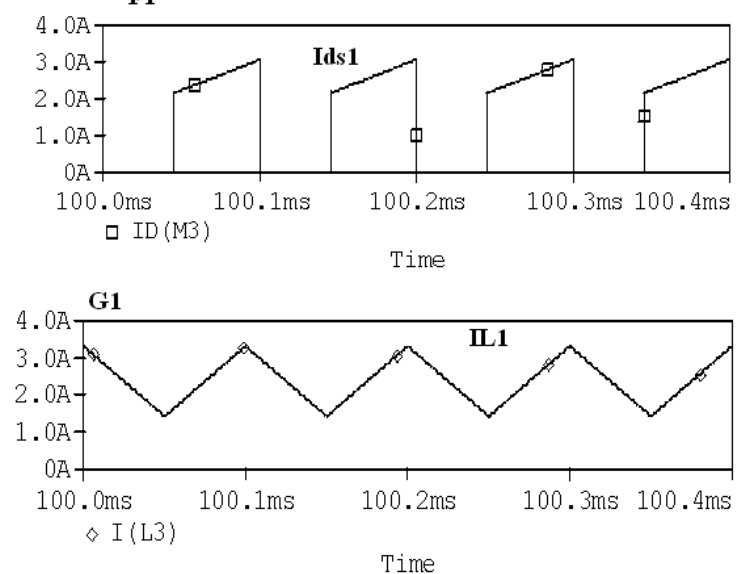

E2

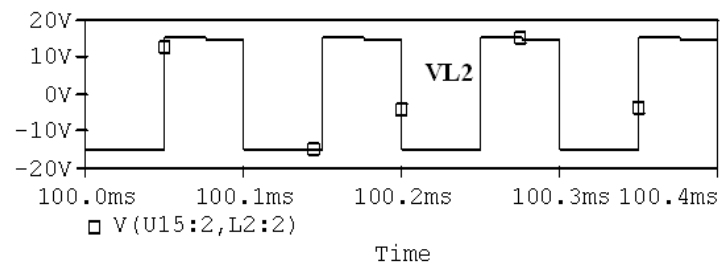

F2

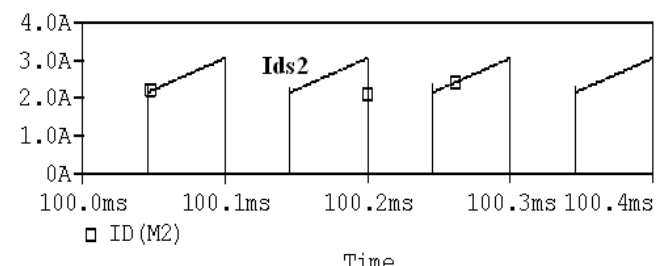

Time

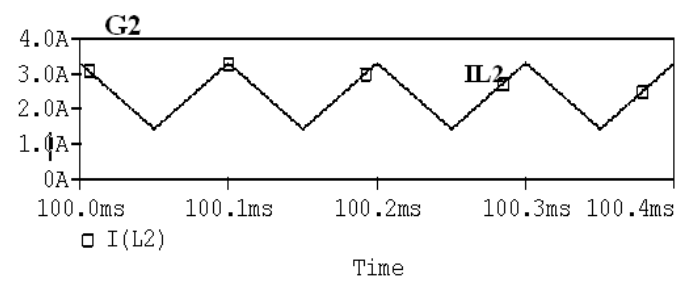

Figure 6. Typical Signals generated in the DC/DC converters of the lower ( 1 ) and upper (2) stage:A1, A21 : PWM of the commands MPPT of two stages, A1, A22 : Vgs voltage of command of every switch of two stages, B1, B2 : Voltages in the input and the output of every switch of two stages, and complete PV system, C1, C2 : current at input and output of each switch on both stages, and complete system, D1, D2 : Vds voltage at the output of every switch of two stages, E1, E2 : : voltage in the borders of the inductance of every converter of two stages, F1, F2 : Ids current at the output of every switch of two stages, G1, G2 : IL current of the inductance of two stages.
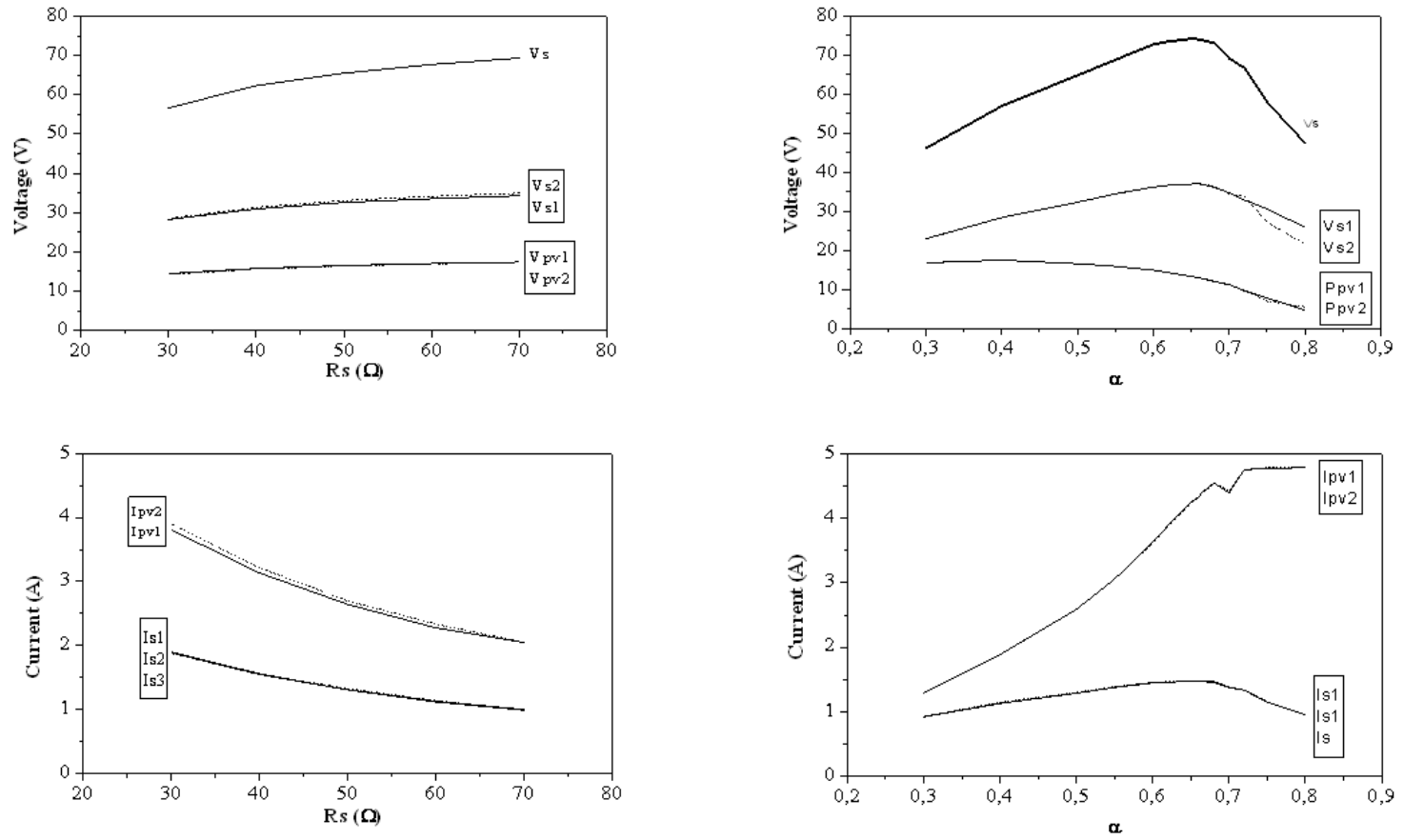

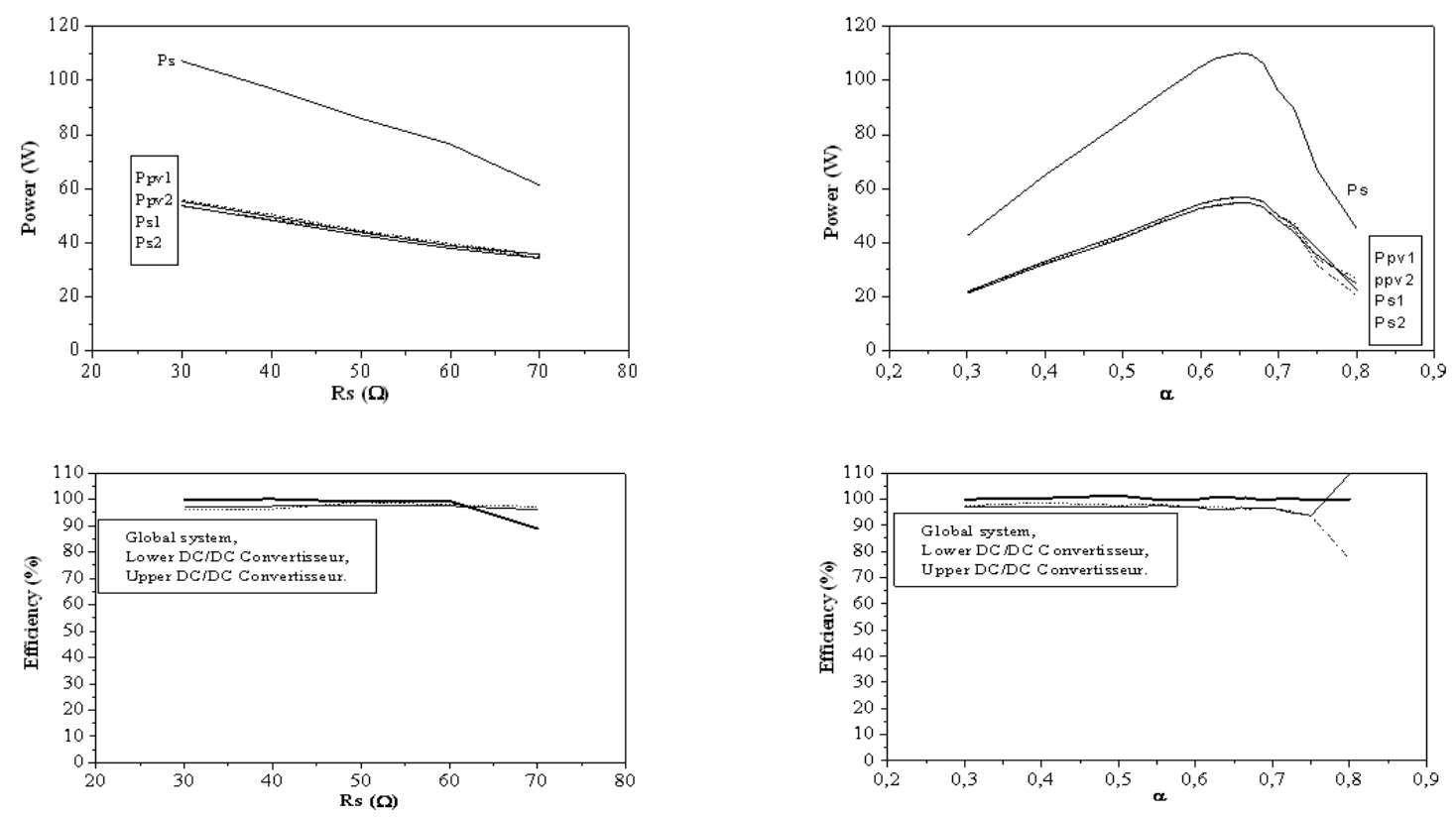

Figure 7. Typical simulation in Pspice of the influence of load and duty cycle of the PWM signal on the electric quantities (current, voltage, power and efficiency) of PV system in Figure $1 . \mathrm{Le}=1000 \mathrm{~W} / \mathrm{m}^{2}, \mathrm{~T}=25^{\circ} \mathrm{C}$.

\subsection{Influence of Load and Duty Cycle of the PWM Signal}

To better understand the overall functioning of the PV system in Figure 1, we analyzed in the Pspice simulator the electrical quantities (voltage, current, power and efficiency) of the system as a function of load and duty cycle of the PWM signal. Typical results are shown in Figure 7 as a function:

- The load for illumination of $1000 \mathrm{~W} / \mathrm{m} 2$ and a temperature of $25^{\circ} \mathrm{C}$,

- The duty cycle of the PWM signal to an illumination of $1000 \mathrm{~W} / \mathrm{m} 2$ and a load of $50 \Omega$.

These results show a functioning depending on load and duty cycle:

- The electrical input and output quantities (voltage, current, power and efficiency) of the two converters is practically identical. The floating voltage of the converter of the high stage does not exceed $35 \mathrm{~V}$ and the power switch of this stage is correctly controlled, in the opening and closing independently in the variations of load and duty cycle.

- The output voltage of the overall system is the sum of output voltages of each converter,

- The output current of the overall system is the current flowing to the output of each converter,

- The efficiency of the global system (about 95\%) is the same as those of the two converters (upper and lower).

All results in this paragraph show the good functioning of each DC/DC converter and the global PV system. These results are checked for illumination between $300 \mathrm{~W} / \mathrm{m}^{2}$ and $1000 \mathrm{~W} / \mathrm{m}^{2}$. For each variation (load and duty cycle), the circuit of shaping played well its role. It takes into account the floating voltage (Vref) and generates a signal that accurately controls the switch on the upper stage. The global power generated by the two panels is supplied to the load via the two DC/DC converters in series with a high efficiency (above 95\%).
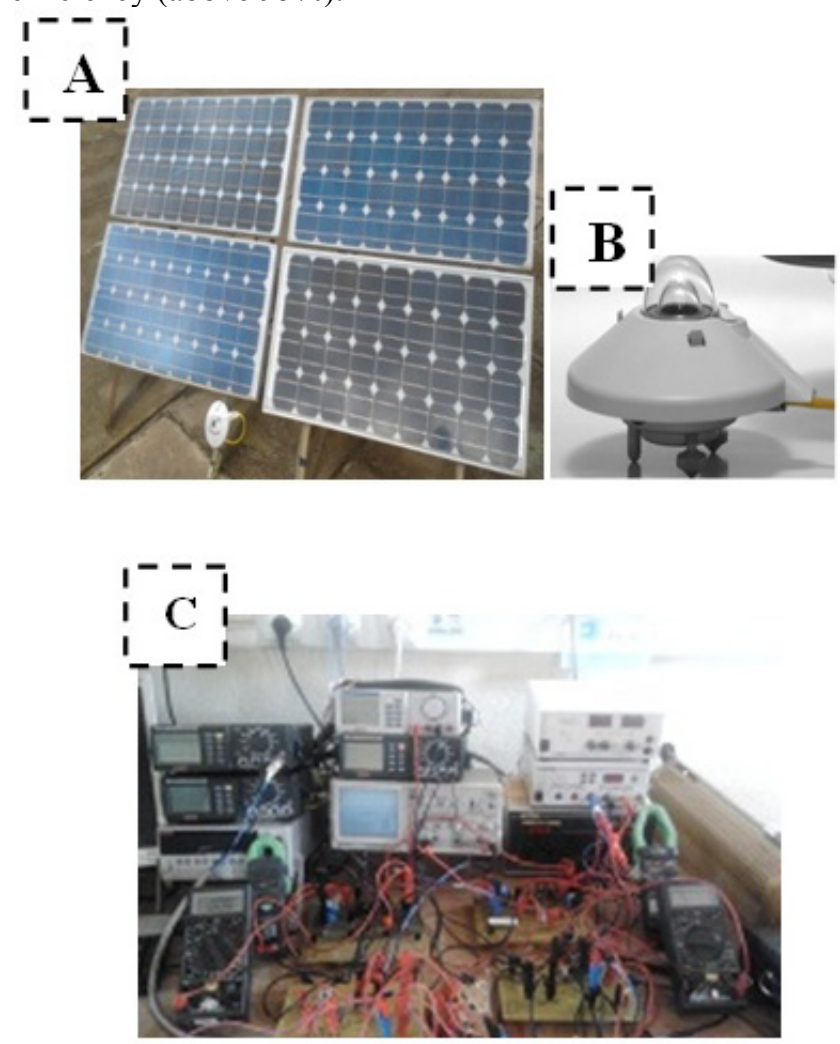

Figure 8. The automated bench of measure in the laboratory: A: PV Panel of $300 \mathrm{~W}$; B: pyranometer; C: equipment (multimeter, computer.). 


\section{Experimental Validation}

\subsection{Experimental Procedure}

The bench of measure which allows us to validate all the results obtained in the previous paragraph is represented in figure 8 [1-4]. This bench, completely automated, is constituted:

- $\quad$ Four PV modules oriented south of $42^{\circ}$ according to the horizontal axis,

- A meteorological station (pyranometer and temperature sensor) to accurately track the values of irradiance and temperature,

- A multimeter (Keithley 2700) connected to a computer for data acquisition and real time trace of various electric quantities of the PV system (voltage, current, power, efficiency ).

The DC/DC Boost converter, the MPPT commands, the circuit of shaping of the signal PWM and the system of polarization of the various active components are represented in figure 9.
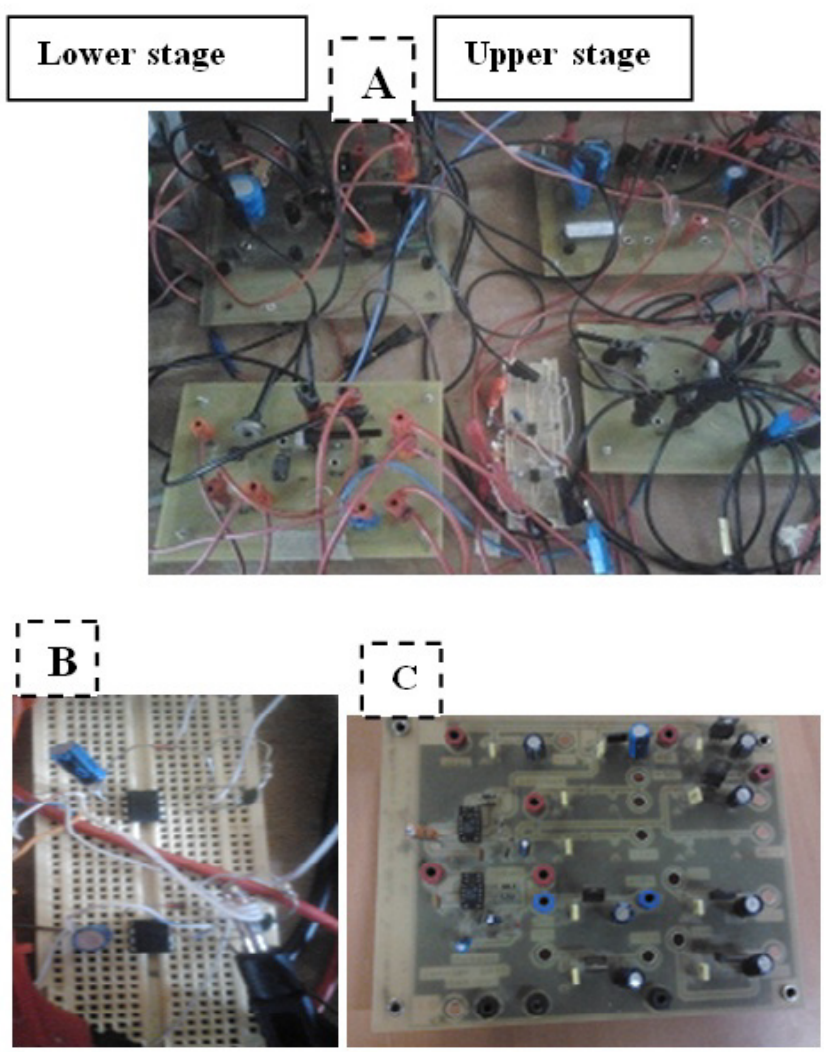

Figure 9. PV equipments realized during this work: A: Lower and upper stages of the PV system (DC/DC converters, manual MPPT commands), B: Circuit of shaping of the PWM signal, C: Polarization system of the various active components.

\subsection{Functioning of Converters}

We realized and characterized the complete PV system in Figure 9 when the illumination is $700 \mathrm{~W} / \mathrm{m}^{2}$, the temperature of $30{ }^{\circ} \mathrm{C}$, the load is a resistor of $50 \Omega$ and manual MPPT command. The MPPT command was designed to generate a PWM signal of $10 \mathrm{kHz}$, and duty cycle of 0.5 . Since, according to the simulation results, the output voltage of each $\mathrm{DC} / \mathrm{DC}$ converter is of the order of $30 \mathrm{~V}$, then we set the parameters of the circuit shaping of the high stage so that the PWM signal has amplitude of the order of $35 \mathrm{~V}$. This amplitude is largely sufficient to control the switch of the DC/DC converter of this stage in the closure and in the opening. To confirm this and the simulation results in Pspice, we noted the different signals DC/DC converters of the PV system (Figure 1). The results obtained are shown in figures 10, show:

- The MPPT controls the two stages with a PWM signal of amplitude of $10 \mathrm{~V}$, frequency of $10 \mathrm{kHz}$ and duty cycle of 0.5 (Figure 10. A1 and A2). This amplitude is sufficient to control the switch on the lower stage $(\mathrm{Vgs}=10 \mathrm{~V})$ (Figure 10. B1). For cons, the switch on the high stage requires increasing amplitude and shaping of the PWM signal. The signal obtained at the output of the shaping circuit (Figure 10. A2) shows an amplitude of about 35V. Since the floating voltage (Vref $=\mathrm{Vs} 1$ ) is of the order of $30 \mathrm{~V}$ (Figure 10. C1), the control signal (Vgs) of this switch (Figure 10. B2) varies between -30 and $5 \mathrm{~V}$. This signal is sufficient to operate this closing-opening switch.

- The voltages of the two PV panels are in the order of $15 \mathrm{~V}$, of the output of every switch in the order of 30 $\mathrm{V}$ and output of the global PV system is in the order of $60 \mathrm{~V}$ (Figures 10. C1, C2 and C3). The measurement of input (output) current of each $\mathrm{DC} / \mathrm{DC}$ converter is of the order of $2.4 \mathrm{~A}(1.2 \mathrm{~A})$. These values show the good functioning of each $\mathrm{DC} / \mathrm{DC}$ converter, the overall system and the validity of relations 5-6 for a duty cycle of 0.5.

- $\quad$ During the closing of the two switches (during a1.T and $\alpha 2 . T$ ): the switches of two converters are closed $(\mathrm{Vds} 1=\mathrm{Vds} 2=0 \mathrm{~V})$ (Figures 10. D1 and D2.), the voltage across the inductors is that the panel (VL1= VL2 $=15 \mathrm{~V})$ (Figures 10. E1 and E2). These voltages ensure the charging of the inductors by currents (Figures 10 F1and F2) with a variation compared with times $\frac{\mathrm{di}_{\mathrm{L}}}{\mathrm{dt}}=3.6210^{4} \mathrm{~A} / \mathrm{S}$, in good agreement with the calculated or simulated $3.7510^{4}$ A/S.

- During the opening of both switches (during $\alpha 1 . T-T$, $\alpha 2 . \mathrm{T}-\mathrm{T})$ : the switches of both $\mathrm{DC} / \mathrm{DC}$ converters open and because the diode (D) is conducting, the voltage of output of both switches $\mathrm{Vds} 1=\mathrm{Vds} 2=\mathrm{Vs} 1$ $=\mathrm{Vs} 2=30 \mathrm{~V}$ (Figures 10. D1 and D2). The voltage in the borders of the inductors is thus $\mathrm{VL} 1=\mathrm{Vpv} 1-\mathrm{Vs} 1=\mathrm{VL} 2=\mathrm{Vpv} 2-\mathrm{Vs} 2=-15 \mathrm{~V}$ (Figures 10. E1 and E2). These voltages insure the discharge of the inductors by currents (figures $10 \mathrm{~F} 1$ and F2) with a variation compared to times $\frac{\mathrm{di}_{\mathrm{L}}}{\mathrm{dt}}=-3.6210^{4} \mathrm{~A} / \mathrm{S}$, in good agreement 
with the calculated or simulated $-3.7510^{4} \mathrm{~A} / \mathrm{S}$.

- From the charge and discharge of the inductor (Figures 10. F1 and F2), we can deduct the undulation of the current of the inductors which is of the order of $1.88 \mathrm{~A}$. This value is in good agreement with the theoretical value which is of the order of $1.88 \mathrm{~A}$ (Relation 4).

All the waves forms of experimental values obtained in this paragraph are in very good agreement for the results obtained in the Pspice simulator (Paragraph III) and the relations which govern the functioning of DC-DC converters (Relations 2-6). The circuit of shaping and the DC/DC converters of the PV system realized correctly their role. To validate the functioning of the system, we analyze in the following paragraph the functioning of the complete PV system according to load and to duty cycle.

\subsection{Functioning of the Global System}

We analysed the functioning of our PV system (Figure 9) as a function of load and duty cycle of PWM signal to an illumination of about $700 \mathrm{~W} / \mathrm{m}^{2}$ and a temperature of $30^{\circ} \mathrm{C}$. We set the parameters of the circuit shaping of the upper stage (Figure 1) to properly take into account the value of the floating voltage (Vref of about $30 \mathrm{~V}$ ) and properly control the power switch of this stage at the closing and opening. The different electrical quantities (voltage, current, power and efficiency), experimental and simulated obtained are represented in Figure 11. These plots show:

- a very good agreement between experiment and simulation in Pspice,

- the output voltage of the PV system is equal to the sum of the voltages of each converter,

- The output current of the PV system is the output current of each converter,

- The power supplied by two panels is that one practically restored to the load through two inverters in series. During this transfer, the efficiency of every converter and on the discretized system is very satisfactory (Upper to $90 \%$ ).

All the experimental results obtained in this paragraph shows the good functioning of discretized system and circuit shaping of the PWM signal that controls the power switch of the upper stage. Also, the good efficiency of the discretized PV system (>90\%), particularly the lower and upper DC/DC converter, shows the efficiency of the PV system designed and its use in PV systems. This allows overcoming the well problem of shading and the failure of PV cells and PV panels.
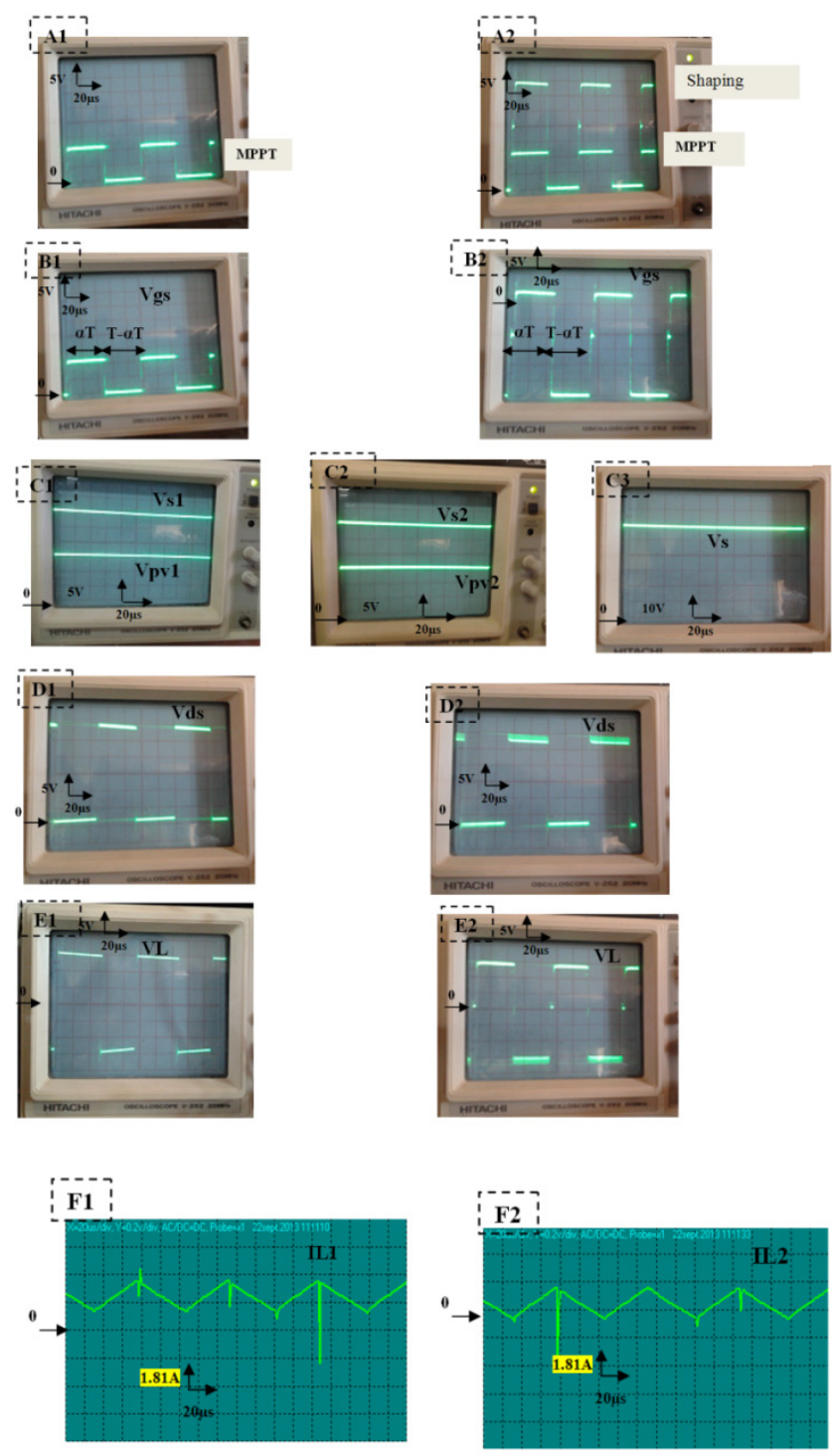

Figure 10. Signals generated by the lower stage (1) (left) and the upper stage (2) (right): A1: MPPT Command on the lower stage,A2: MPPT command of the upper stage, and output of the circuit of shaping. B1, B2: Vgs voltage of command of every switch of both stages, $\mathrm{C} 1, \mathrm{C} 2$ and $\mathrm{C} 3$ : voltage in input and output of every DC/DC converter, and output of the global PV system, D1, D2: voltages of output of every switch, E1, E2: voltages in the borders of the inductor of every switch, F1, F2: current in the inductance of every switch (lower and upper stage). 

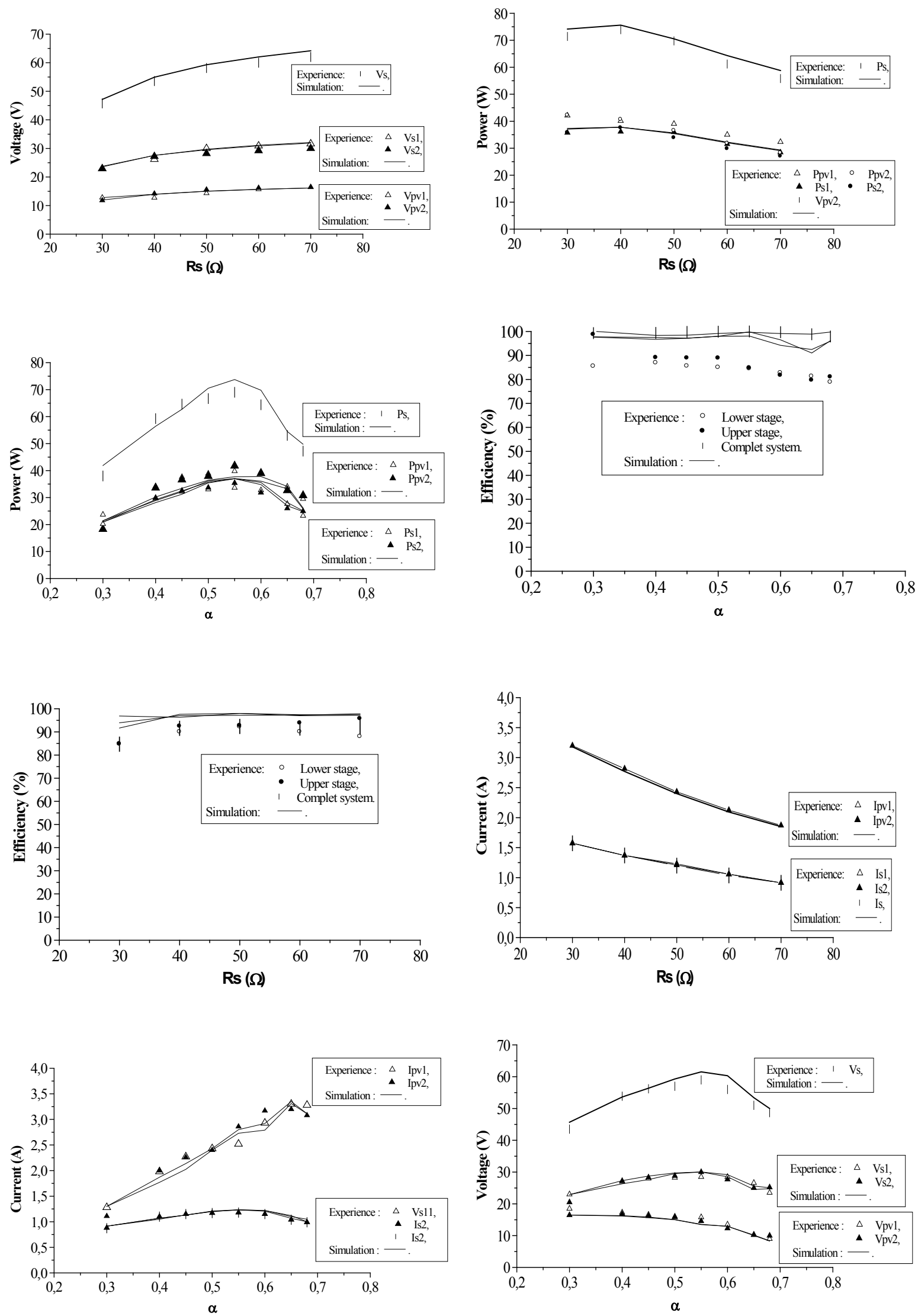

Figure 11. Electrical quantities (currents, voltages, power and efficiency) experimental and simulated in Pspice of the lower, upper stages and complete system as a function of the load (left) and duty cycle (right). $\mathrm{Le}=700 \mathrm{~W} / \mathrm{m}^{2}, \mathrm{~T}=30^{\circ} \mathrm{C}$. 


\section{Conclusion}

In this paper, we studied the feasibility of a discretized photovoltaic system (PV), constituted by two stages of adaptation. Every stage is formed by DC/DC boost converter controlled by a Manual MPPT command and an adequate circuit to control the opening-closing power switches of every DC/DC converter. The results obtained in the Pspice simulator and experimental show:

- Good agreement in simulation and experience of the electrical quantities of each block of the PV system,

- The good functioning of each stage of adaptation and complete PV system.

- A good efficiency of each stage and particularly the complete system (greater than 90\%).

All these results allow us to conclude that the discretization of the PV installations is an advantageous solution with the aim of optimization and of increase of the PV electric production. So, it allows solving the problem of the efficiencies degradation of the PV installations during shades and failures of PV cells and panels.

\section{Acknowledgements}

This work is supported by:

- Belgian Development Agency CTB (Project MIP/012/010);

- Programme des Nations Unis au Développement PNUD Art Gold Maroc, 20082 ENV OO;

- Coopération MAROCO-BELGE, Commission Universitaire pour le Développement, CUD- Oujda 2008-2012 (Activité Eau et Environnement/sous-activité Energies Renouvelables);

- Coopération MAROCO-TUNISIENNE RECHERCHE SCIENTIFIQUE TECHNOLOGIE, projet (11/MT/38).

\section{REFERENCES}

[1] Yaden MF, Melhaoui M, Gaamouche R, Hirech K, Baghaz E, Kassmi K. Photovoltaic System Equipped with Digital Command Control and Acquisition. Electronics. 2013; 2(3):192-211.

[2] T. Mrabti, M. El Ouariachi, R. Malek, Ka. Kassmi, F. Bagui, F. Olivié and K. Kassmi. Design, realization and optimization of a photovoltaic system equipped with analog maximum power point tracking (MPPT) command and detection circuit of the dysfunction and convergence the system (CDCS). International Journal of the Physical Sciences Vol. 6(35), pp. 7865 - 7888, 23 December, 2011.

[3] Kassmi Khalil, Baghaz El Hadi, Yaden Faysal, Melhaoui Mustapha. Design, realization and optimization of the photovoltaic systems. Mediterranean Green Energy Forum
(MGEF-13), Fez, Morocco,16-20 June 2013.

[4] E. Baghaz, F. Yaden, K. Hirech, M. Melhaoui, K. Kassmi. Design and realization of an autonomous PV system equipped with a regulator of charge/dischargeand digital MPPT command. Mediterranean Green Energy Forum (MGEF-13), Fez,Morocco,16-20 June 2013.

[5] Stéphane VIGHETTI, Benjamin VALLET. Photovoltaïque raccordé au réseau Choix et optimisation des étages de conversion. "JCGE 08, Lyon : France (2008).

[6] Doron Shmilovitz, Yoash Levron. Distributed Maximum Power Point Tracking in Photovoltaic Systems - Emerging Architectures and Control Methods. AUTOMATIKA 53(2012) 2, 142-155.

[7] Yang Du, Dylan Dah-Chuan Lu. Battery-integrated boost converter utilizing distributed MPPT configuration for photovoltaic systems. Solar Energy 85 (2011) 1992-2002

[8] Geoffrey R. Walker, Member, IEEE, and Paul C. Sernia" Cascaded DC-DC Converter Connection of Photovoltaic Modules" IEEE TRANSACTIONS ON POWER ELECTRONICS, VOL. 19, NO. 4, JULY 2004.

[9] Nicola Femia, Member, IEEE, Gianpaolo Lisi, Giovanni Petrone, Giovanni Spagnuolo, Member, IEEE, and Massimo Vitelli. Distributed Maximum Power Point Tracking of Photovoltaic Arrays: Novel Approach and System Analysis. IEEE TRANSACTIONS ON INDUSTRIAL ELECTRONICS, VOL. 55, NO. 7, JULY 2008.

[10] Ho-sung Kim, Jong-Hyun Kim, Byung-Duk Min, Dong-Wook Yoo, Hee-Je Kim. A highly efficient PV system using a series connection of DC-DC converter output with a photovoltaic panel. Renewable Energy 34 (2009) 2432-2436.

[11] Pierre Petit, Michel Aillerie, Jean-Paul Sawicki, and Jean-Pierre Charles. Push-pull converter for high efficiency photovoltaic conversion.

[12] T. Mrabti, M. El Ouariachi, F. Yaden, Ka.Kassmi, K. Kassmi, Characterization and Modeling of the Electrical Performance of the Photovoltaic Panels and Systems, Journal of Electrical Engineering: Theory and Application. Vol.1-2010/Iss.2.

[13] Site Internet, http://sunwize.com/info_center/pdfs/shell_SP7 5_PC.pdf

[14] Ho-sung Kim, Jong-Hyun Kim, Byung-Duk Min, Dong-Wook Yoo, Hee-Je Kim. A highly efficient PV system using a series connection of DC-DC converter output with a photovoltaic panel. Renewable Energy 34 (2009) 2432-2436.

[15] Lijun Qin, Xiao Lu. Matlab/Simulink-Based Research on Maximum Power Point Tracking of Photovoltaic Generation. Physics Procedia 24 (2012) 10-18.

[16] Dorin Petreus, TomaPatarau, Stefan Daraban, Cristina Morel, Brian Morley.A novel maximum power point tracker based on analog and digital control loops.Solar Energy 85 (2011) 588-600.

[17] Nabil A. Ahmed, A.K. Al-Othman, M.R. AlRashidi.Development of an efficient utility interactive combined wind/photovoltaic/fuel cell power system with MPPT and DC bus voltage regulation.Electric Power Systems Research 81 (2011) 1096-1106.

[18] Chih-Ming Hong, Ting-Chia Ou, Kai-Hung Lu. Development 
of intelligent MPPT (maximum power point tracking) control for a grid-connected hybrid power generation system. Energy 50 (2013) $270 \mathrm{e} 279$.

[19] Mhamed Rebhi ,Ali Benatillah ,Mabrouk Sellam,Boufeldja Kadri. Comparative Study of MPPT Controllers for PV System Implemented in the South-west of Algeria. Energy Procedia 36 ( 2013 ) 142 - 153.
[20] Issam Houssamo, Fabrice Locment, Manuela Sechilariu. Experimental analysis of impact of MPPT methods on energy efficiency for photovoltaic power systems. Electrical Power and energy systems 46(2013)98-107. 